\title{
Effectiveness of a novel training program for emergency medicine residents in ultrasound-guided insertion of central venous catheters
}

\author{
Michael Y. Woo, MD; ${ }^{*}$ Jason Frank, MD, MA(Ed); ${ }^{*}$ A. Curtis Lee, PhD; ${ }^{*}$ Calvin Thompson, MD; ${ }^{\dagger}$ \\ Pierre Cardinal, MD; ${ }^{\ddagger}$ MarianneYeung, MD; Jennifer Beecker, MD*
}

\section{ABSTRACT}

Objective: Insertion of central venous catheters (CVCs) is an essential competency for emergency physicians. Ultrasound-guided (USG) insertion of CVCs has been shown to be safer than the traditional landmark technique. There is no clear consensus on effective methods for training physicians in USG insertion of CVCs. We developed and evaluated a novel educational training program in the USG technique for insertion of CVCs.

Methods: Sixteen emergency medicine residents volunteered for a pre- and postprogram evaluation study, which was approved by our research ethics board. After their previous experience was determined, each participant was videotaped inserting a USG CVC in the right internal jugular vein on models. Participants then reviewed a Web-based instructional module and had a practical session. Participants were again videotaped inserting a USG CVC. The primary outcome was the change in score before and after the training program, using an expert-validated performance evaluation tool used to review the videotaped performances in a blinded fashion. Participants also completed a questionnaire to measure their satisfaction with the training program and any change in their perceived competence.

Results: Participants ranged from residency year 1 to 5 . Thirteen of $16(81 \%)$ had never attempted USG insertion of a CVC. Participants reported that the models were realistic. Performance scores (12/19 to $13.2 / 19)$ and global ratings assessments (3.5/7 to 5.5/7) improved significantly $(p<0.01$; the effect size, Cohen $d=1.12$ before and 1.28 after) after the instruction. There was good interrater reliability between evaluators of the videotaped performances regarding performance scores $(r=0.68)$ and global rating scores $(r=0.75)$. All participants felt their confidence and technical skills were improved $(p<0.01)$ and all felt satisfied with the training program.

Conclusion: This brief innovative multimethod training pro- gram was effective in enhancing emergency medicine resident competence in USG insertion of CVCs.

Keywords: central venous catheter, ultrasonography, training, education

\section{RÉSUMÉ}

Objectif : L'insertion d'un cathéter veineux central (CVC) est une compétence indispensable aux médecins d'urgence. L'insertion échoguidée d'un CVC s'est révélée plus sécuritaire que la technique classique. Or, il n'existe pas de consensus clair quant aux méthodes efficaces pour enseigner cette technique échoguidée aux médecins. Nous avons conçu et évalué un nouveau programme de formation pour l'enseignement de la technique d'insertion échoguidée d'un CVC.

Méthode : Seize résidents en médecine d'urgence se sont portés volontaires pour une étude d'évaluation pré- et postprogramme approuvée par notre comité d'éthique de la recherche. Après avoir établi leur expérience antérieure, on a filmé tous les participants sur vidéo alors qu'ils procédaient à I'insertion échoguidée d'un CVC par accès jugulaire interne droit sur des mannequins. Les participants ont ensuite passé en revue le module de formation sur le Web et ont eu droit à une séance pratique. Puis, on les a filmés de nouveau durant I'insertion échoguidée d'un CVC. On a retenu comme principal critère d'évaluation la différence entre les scores obtenus avant et après le programme de formation, calculée au moyen d'un outil d'évaluation du rendement validé par des experts à l'insu et utilisé pour analyser les rendements filmés. Les participants ont en outre répondu à un questionnaire pour mesurer leur degré de satisfaction quant au programme de formation et leur perception quant au changement de leurs habiletés techniques.

Résultats : Les participants étaient des résidents de la première

From the Departments of *Emergency Medicine and †Anesthesia, and the ¥Division of Critical Care, University of Ottawa, Ottawa, Ont.

Presented at the Canadian Association of Emergency Physicians Annual Conference, Victoria, BC, June 2-6, 2007.

Submitted Jul. 8, 2008; Revised Dec. 17, 2008; Accepted Jan. 8, 2009

This article has been peer reviewed.

CJEM 2009;11(4):343-8 
à la cinquième année. Treize résidents sur $16(81 \%)$ n'avaient encore jamais pratiqué d'insertion échoguidée de CVC. Les participants ont affirmé que les modèles étaient réalistes. Les scores de rendement (12/19 à 13,2/19) et les évaluations globales $(3,5 / 7$ à $5,5 / 7)$ ont significativement augmenté $(p<0,01$; taille de l'effet [ $d$ de Cohen] $=1,12$ avant et 1,28 après) après la formation. On a noté une bonne fiabilité entre les évaluateurs des rendements sur vidéo pour ce qui est des scores de rendement $(r=0,68)$ et des scores globaux $(r=0,75)$. Tous les participants ont estimé être plus confiants et mieux maîtriser leurs habiletés techniques $(p<0,01)$. Ils se sont aussi dits satisfaits du programme de formation.

Conclusion : Ce bref programme novateur de formation multimodale a amélioré efficacement la compétence des résidents en médecine d'urgence dans l'insertion échoguidée d'un CVC.

\section{INTRODUCTION}

Over 5 million central venous catheters (CVCs) are inserted yearly in the United States. ${ }^{1}$ Establishing central venous access is an essential skill for emergency physicians and is a core competency for emergency medicine residency training. ${ }^{2}$

The indications for CVC insertion include hemodynamic monitoring, temporary cardiac pacemaker, hemodialysis and lack of peripheral venous access. With the recent landmark sepsis trial, hemodynamic monitoring with central lines is likely to increase. ${ }^{3}$ Insertion of CVCs continues to be associated with complication rates as high as $18 \%{ }^{4,5}$ Potential immediate complications are listed in Box 1.

The use of ultrasound technology has significantly improved the safety and effectiveness of CVC insertion beyond the traditional anatomical landmarking technique alone. Ultrasonography can readily identify the locations of veins relative to arteries, and therefore individual anatomical differences can be taken into account (Fig. 1). ${ }^{6-8}$ The use of ultrasonography in experienced hands reduces the number of attempts and arterial punctures compared with the landmark method. After 3 or more attempts at insertion, mechanical complications increase by 6 times compared with a single attempt. ${ }^{5}$ Ultrasound-guided (USG) insertion of CVCs is reported to be the preferred method for difficult cannulations, such as in those patients with obscure surface landmarks or hypotension..$^{9-13}$

Several meta-analyses and randomized controlled trials have demonstrated that USG insertion of CVCs is

Box 1. Potential immediate complications from insertion of central venous catheters

Arterial puncture

Hematoma

Hemothorax

Pneumothorax

Brachial plexus injury

Line misplacement safely performed by emergency physicians with greater success and fewer immediate complications than the traditional landmarking method. . $9,11,12,14-17^{-17}$

National recommendations have been made for USG insertion of CVCs by both the National Quality Forum in the United States and the National Institute of Clinical Excellence in the United Kingdom. ${ }^{18,19}$

There are significant training issues and implications hindering the widespread use of the USG technique for insertion of CVCs. Detailed descriptions and reports of the effectiveness of formal training programs are limited, although advocates for USG insertion of CVCs have indicated the need for adequate training. ${ }^{20}$

The purpose of our study was to describe a new multimethod training program involving both Webbased material and a hands-on practical session using a partial task trainer, and to determine the program's effectiveness for training emergency medicine residents.

\section{METHODS}

\section{Study design}

Our study was a prospective program evaluation using a

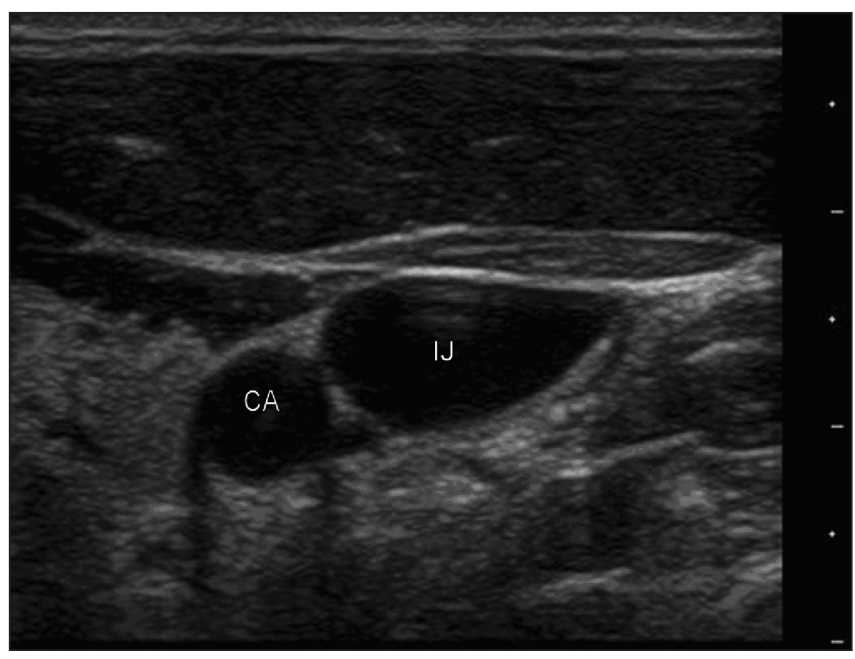

Fig. 1. Transverse ultrasound image of internal jugular (IJ) vein and carotid artery (CA). 
before-after design. ${ }^{21}$ We received approval from the Ottawa Hospital Research Ethics Board and obtained informed written consent from all participants.

\section{Study setting and population}

Participation in the study was offered to all 21 emergency medicine residents at the University of Ottawa. For logistical reasons, such as equipment and room availability, study enrolment was limited to 16 residents. Priority was given to graduating residents to allow them to take part before completing their residency. Those residents who could not participate or did not consent to the study took part in the same course at a different time.

\section{Study protocol}

After a brief orientation session, participants' previous experience was assessed through a questionnaire. Before receiving any training, participants were videotaped inserting a CVC in the right internal jugular vein using the USG technique on a partial task trainer simulation model (Central Venous Access Head Neck \& Upper Torso Model BPH600-F, Blue Phantom). SonoSite MicroMaxx (SonoSite Canada, Inc.) ultrasonography machines were used for USG CVC insertion.

We developed Web-based material (http://intermed .med.uOttawa.ca/courses/cvc/) before we conducted the course. The material was based on current evidence and expert experience and included information on CVC indications, general preparation, sterile technique, landmark method, USG method and complications. This was complemented by a video demonstrating USG insertion of a CVC in the right internal jugular vein in a real patient with concomitant ultrasound images. Participants reviewed the Web-based material after the initial videotaped session for a maximum of 1 hour.

Participants then took part in a 1-hour hands-on practical session with a 1:4 instructor:student ratio. No real patients were used. Participants were then videotaped again inserting a CVC in the right internal jugular vein of models using the single operator transverse orientation approach that was demonstrated in both the Web-based material and the hands-on practical session. All equipment was prepared before insertion of the CVC. An assistant was there only to help the participant apply the sterile probe cover. Participants were allowed up to 30 minutes to complete the CVC insertion.

At the completion of the second videotaped session, participants completed a postcourse questionnaire to assess changes in knowledge, perceived competence, satisfaction with the course, and realism of the model on Likert scales.

\section{Assessment instrument}

Both pre- and posttraining videotapes were assessed with the use of a performance evaluation checklist and a global rating system developed by the author (Appendix 1). This instrument was based on widely accepted published CVC insertion protocols for content validity, and pilot tested for discrimination on medical students, residents, faculty and expert faculty. ${ }^{22}$ Face validity and content validity of the tool was established by 4 experts from emergency medicine, anesthesia and critical care before the administration of the study. The total global assessment score was from 0 to 7 and a score greater than or equal to 5 indicated a "good"/“acceptable" technique.

\section{Measurements}

This study evaluated the impact of the training program on learner satisfaction and change in performance. ${ }^{21}$ The primary outcome was the difference in the performance of USG insertion of CVCs in the right internal jugular vein before and after the multimethod educational intervention.

The pre- and postvideos were reviewed in a blinded fashion by 2 expert reviewers using the performance evaluation tool. Reviewers were blinded to the identities of the participants and did not know whether the procedure was performed before or after the intervention. Each reviewer completed a 19-item content checklist and a 7-point global rating that ranged from poor to excellent. Paired $t$ tests were used to compare the performance checklist and the global rating pre- and postassessments. Participant perception was evaluated to assess change in perceived competence, as well as satisfaction with the course based on Likert scales.

\section{RESULTS}

Sixteen emergency medicine residents took part in the study. Participant demographics are provided in Table 1.

Psychometrically, there was good interrater reliability between evaluators of the videotapes regarding performance scores $(r=0.68)$ and global rating scores $(r=0.75)$.

The performance checklist scored averages of 12.0/19 before the training program, to $13.5 / 19(p=0.01)$ after the training program. The global rating scores increased 
from 3.5/7 before the program, to 5.5/7 $(p=0.01)$ after the program.

The effect size, as measured by Cohen $d$, was 1.12 and 1.28 for the checklist and global ratings, respectively, indicating a high practical significance in participant performance. ${ }^{23}$

The average time from the needle touching the surface of the simulation model to vessel puncture was 91 seconds before the program, and 60 seconds after the program.

Residents felt that the training program significantly $(p<0.01)$ improved their confidence and technical skills with USG insertion of CVCs (Fig. 2).

The postinstruction survey found that $81.2 \%(13 / 16)$ of participants rated the USG model as adequately realistic or very realistic. Overall, 93.8\% (15/16) of participants were satisfied or very satisfied with the training program.

\begin{tabular}{|c|c|}
\hline Characteristic & $\begin{array}{l}\text { No. (\%) } \\
\text { of participants }\end{array}$ \\
\hline \multicolumn{2}{|l|}{ Sex } \\
\hline Male & $10(62.5)$ \\
\hline Female & $6(37.5)$ \\
\hline \multicolumn{2}{|l|}{ Postgraduate year } \\
\hline 1 & $3(18.8)$ \\
\hline 2 & 1 (6.3) \\
\hline 3 & $7(43.8)$ \\
\hline 4 & $2(12.5)$ \\
\hline 5 & $3(18.8)$ \\
\hline \multicolumn{2}{|l|}{ Previous experience } \\
\hline \multicolumn{2}{|l|}{ Formal EMUS course } \\
\hline Yes & $12(75.0)$ \\
\hline No & $4(25.0)$ \\
\hline \multicolumn{2}{|l|}{ Formal USG CVC insertion course } \\
\hline Yes & $2(12.5)$ \\
\hline No & $14(87.5)$ \\
\hline \multicolumn{2}{|l|}{ Formal landmark CVC insertion course } \\
\hline Yes & $6(37.5)$ \\
\hline No & $10(62.5)$ \\
\hline \multicolumn{2}{|l|}{ Prior experience with USG CVC insertion } \\
\hline $\begin{array}{l}\text { No experience seeing or doing a USG CVC } \\
\text { insertion }\end{array}$ & $10(62.5)$ \\
\hline $\begin{array}{l}\text { Seen } 1 \text { or } 2 \text { performed, never actually } \\
\text { attempted to do one }\end{array}$ & $3(18.8)$ \\
\hline Attempted 1 USG CVC insertion & $2(12.5)$ \\
\hline $\begin{array}{l}\text { Attempted } 2 \text { USG CVC insertions, with or } \\
\text { without assistance }\end{array}$ & $0 \quad(0.0)$ \\
\hline $\begin{array}{l}\text { Attempted and completed } \geq 3 \text { USG CVC } \\
\text { insertions independently }\end{array}$ & 1 (6.3) \\
\hline
\end{tabular}

\section{DISCUSSION}

This study describes a novel training program for USG insertion of CVCs combining a Web-based module and a practical skills session. Although there is much evidence in the literature regarding the decrease in complication and improved safety with the USG technique for insertion of CVCs, there is little information on how to teach physicians this skill. Studies are limited to the description of the procedure and the approximate time involved of the course as well as the "how I do it" approach. .11, $17,24,25^{2}$ There is also a higher awareness and promotion of simulation for training purposes to improve patient safety. ${ }^{26}$

This small-scale study demonstrates the effectiveness and efficiency of this multimethod training program. Both the performance checklist and global assessment scores were found to have strong interrater reliability. Although any training in this skill may have had a positive impact, this study demonstrated that there is a large effect of expert-guided deliberate practice with this novel intervention. ${ }^{27,28}$ In keeping with Kirkpatrick's training outcomes model, this change in performance was also associated with high participant satisfaction, perceived efficacy and change in confidence. ${ }^{21}$ Participants felt that with both the short Web-based and practical training, their confidence and performance of a USG insertion of a CVC improved.

There are significant obstacles to changing physician behaviour and adopting new technology. Limitations include the need to demonstrate the effectiveness of the learning opportunity and the time required to obtain the skill. ${ }^{29}$ This design minimized the didactic component by developing a Web-based educational tool for participants to review on their own time before the "hands-on" practical session. This enabled busy

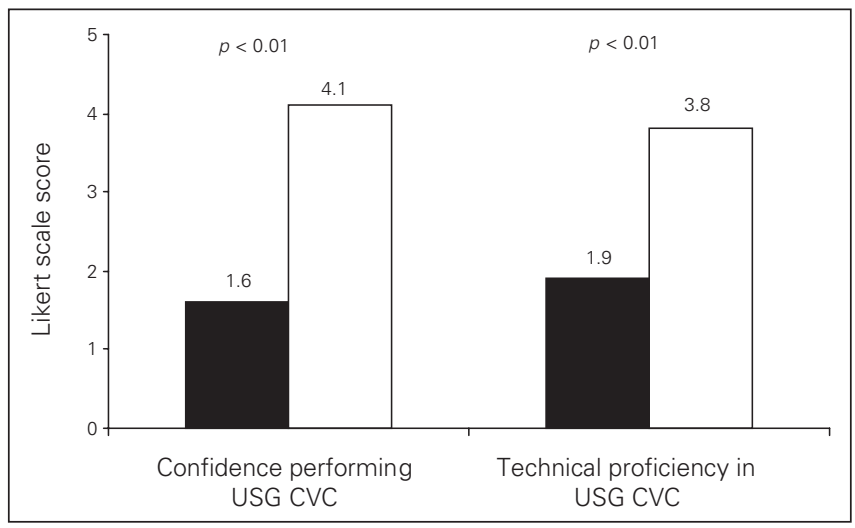

Fig. 2. Responses of emergency medicine residents regarding confidence and technical skills before and after training. $\mathrm{CVC}=$ central venous catheter; USG = ultrasound-guided. 
physicians to maximize their time for skill practice and reduced the costs associated with having experienced instructors running the course. In this way, the program was both effective and efficient.

\section{Limitations}

The study has several limitations that require discussion. The before-after study design did not employ a control group. Although the differences in performance may have been simply related to a practice or Hawthorne effect, the dramatic change in performance makes this unlikely. If the training program was ineffective, residents would be expected to repeat the same mistakes in their postcourse videotaped performance. Instead, this instruction demonstrated dramatic enhancement of the abilities seen on videotape. A repeat session to assess the retention of skills and knowledge could be performed to further determine the effectiveness of this training program. Further outcome studies are needed to assess long-term safety benefits and behavioural changes. Finally, the study focused on a small sample size involving emergency medicine residents of varying experience. A further multicentre study with a control group is needed to ensure generalizability.

\section{CONCLUSION}

This brief innovative multimethod training program was effective in enhancing the competence of emergency medicine residents in USG insertion of CVCs. Participants reported an overall satisfaction with the program. This is the first systematic evaluation of a novel and effective training program for USG insertion of CVCs.

Acknowledgements: We wish to thank Patricia O'Brien and the MedEd team at the University of Ottawa, Ottawa, Ont., for their assistance with this study.

Competing interests: None declared.

Funding: Unrestricted grant from Sonosite Canada, Inc., Markham, Ont.

\section{REFERENCES}

1. Raad I. Intravascular-catheter-related infections. Lancet 1998;351:893-8.

2. Farion K, Morrison LJ. Redefining emergency medicine procedures: Canadian competence and frequency survey. Acad Emerg Med 2001;8:731-8.

3. Rivers E, Nguyen B, Havstad S, et al. Early goal directed therapy in the treatment of severe sepsis and septic shock. N Engl 7 Med 2001;345:1368-77.

4. Merrer J, De Johnghe B, Golliot F, et al. Complications of femoral and subclavian venous catheterization in critically ill patients: a randomized controlled trial. JAMA 2001;286:700-7.

5. McGee DC, Gould MK. Preventing complications of central venous catheterization. $N$ Engl 7 Med 2003;348:1123-33.

6. Gordon AC, Saliken JC, Johns D, et al. US-guided puncture of the internal jugular vein: complications and anatomic considerations. 7 Vasc Interv Radiol 1998;9:333-8.

7. Troianos CA, Kuwik RJ, Pasqual JR, et al. Internal jugular vein and carotid artery anatomic relation as determined by ultrasonography. Anesthesiology 1996;85:43-8.

8. Denys BG, Uretsky BF. Anatomical variations of internal jugular vein location: impact on central venous access. Crit Care Med 1991;19:1516-9.

9. Hind D, Calvert N, McWilliams R, et al. Ultrasonic locating devices for central venous cannulation: meta-analysis. $B M 7$ 2003;327:361.

10. Calvert N, Hind D, McWilliams RG, et al. The effectiveness and cost-effectiveness of ultrasound locating devices for central venous access: a systematic review and economic evaluation. Health Technol Assess 2003;7:1-84.

11. Miller AH, Roth BA, Mills TJ, et al. Ultrasound guidance versus the landmark technique for the placement of central venous catheters in the emergency department. Acad Emerg Med 2002;9:800-5.

12. Keenan SP. Use of ultrasound to place central lines. 7 Crit Care 2002;17:126-37.

13. Fry WR, Clagett GC, O'Rourke PT. Ultrasound-guided central venous access. Arch Surg 1999;134:738-40.

14. Randolph AG, Cook DJ, Gonzales CA, et al. Ultrasound guidance for placement of central venous catheters: a metaanalysis of the literature. Crit Care Med 1996;24:2053-8.

15. Hilty WM, Hudson P, Levitt M, et al. Real-time ultrasoundguided femoral vein catheterization during cardiopulmonary resuscitation. Ann Emerg Med 1997;29:331-6.

16. Hrics P, Wilber S, Blanda MP, et al. Ultrasound-assisted internal jugular vein catheterization in the ED. Am J Emerg Med 1998;16:401-3.

17. Leung J, Duffy M, Finckh A. Real-time ultrasonographyically-guided internal jugular vein catheterization in the emergency department increases success rates and reduces complications: a randomized, prospective study. Ann Emerg Med 2006;48:540-7.

18. The National Quality Forum. Safe practices for better bealth care. A consensus report. Washington (DC): the Forum; 2003. Available: www.qualityforum.org (accessed 2009 Jun 3).

19. National Institute for Clinical Excellence. NICE technology appraisal guidance No.49: guidance on the use of ultrasound locating devices for placing central venous catheters. London (UK): The Institute; 2002. Available: www.nice.org.uk/nicemedia /pdf/Ultrasound_49_GUIDANCE.pdf (accessed 2009 Jun 3).

20. Rothschild JM. Chapter 21. In: Ultrasound guidance of central vein catheterization. Available: www.ahrq.gov/clinic/ptsafety /pdf/chap21.pdf (accessed 28 Apr 2008).

21. Kirkpatrick DL. Evaluating training programs: the four levels. 3rd ed. San Francisco (CA): Berrett-Koehler; 2006.

22. Dronen SC, Younger JG. Central venous catherization and central venous pressure monitoring. In: Clinical procedures in emergency medicine. Roberts JR, Hedges JR, editors. Philidelphia (PA): WB Saunders Company; 1998. p. 358-85.

23. Cohen J. The concepts of power analysis; the t-test for means. Statistical power analysis for the behavioral sciences. New York (NY): Laurence Erlbaum Associates; 1977. p. 1-74.

24. Atkinson P, Boyle A, Robinson S, et al. Should ultrasound guidance be used for central venous catheterization in the emergency department. Emerg Med 72005;22:158-64. 
25. Feller-Kopman D. Ultrasound-guided internal jugular access. A proposed standardized approach and implications for training and practice. Chest 2007;132:302-9.

26. Bond WF, Lammers RL, Spillane LL, et al. The use of simulation in emergency medicine: a research agenda. Acad Emerg Med 2007;14:353-64.

27. Ericsson KA. Deliberate practice and the acquisition and maintenance of expert performance in medicine and related domains. Acad Med 2004;79:S70-81.
28. Cook DJ, Montori VM, McMullin JP, et al. Improving patients' safety locally: changing clinician behaviour. Lancet 2004;363:1224-30.

29. Kovacs G. Procedural skills in medicine: liking theory to practice. J Emerg Med 1997;15:387-91.

Correspondence to: Dr. Michael Woo, Department of Emergency Medicine, Ottawa Hospital, 1053 Carling Ave., Ottawa ON K1Y 4E9; mwoo@ottawahospital.on.ca

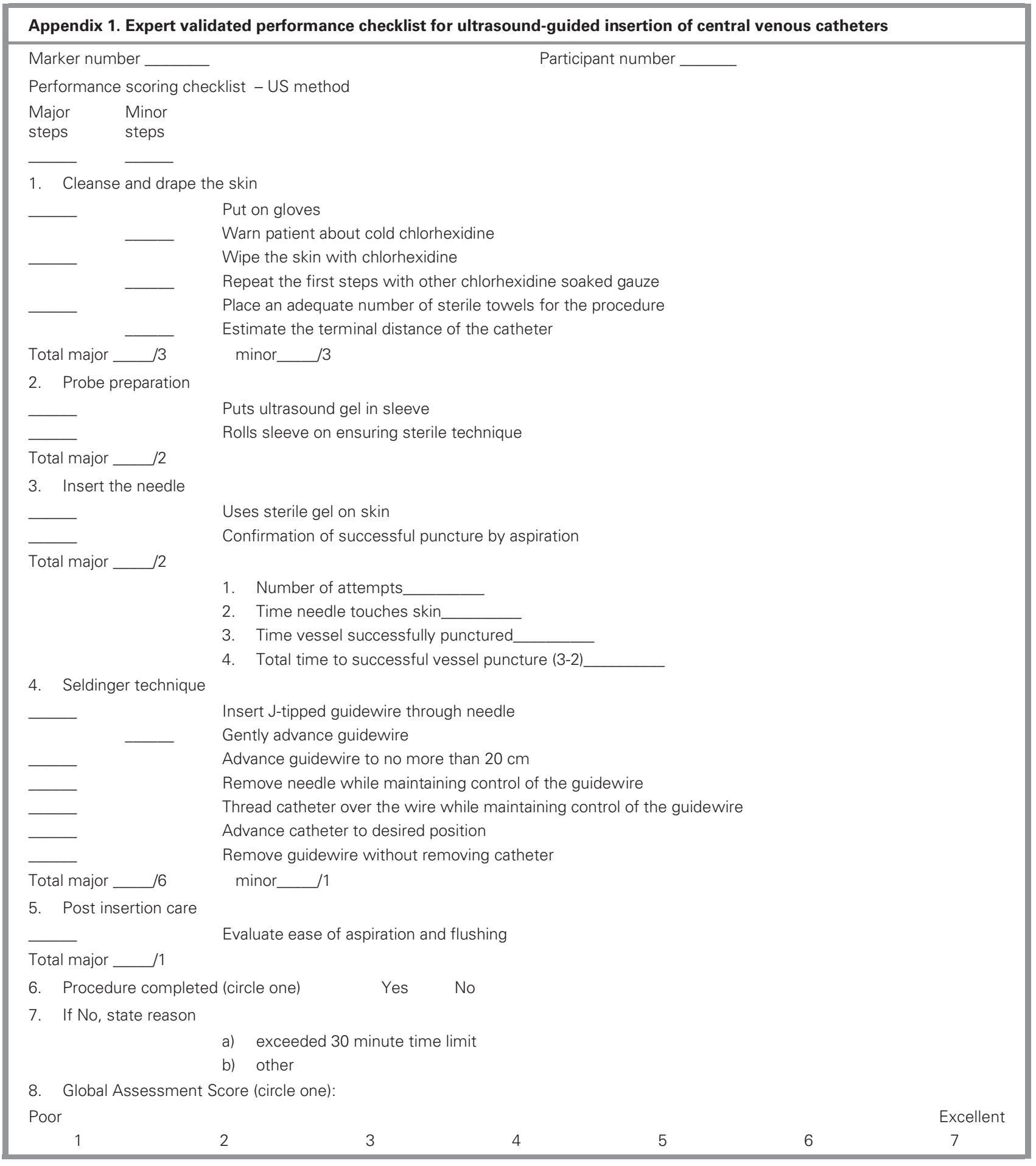

